\section{Seeking clarity in the debate over the safety of GM foods}

Sir-A more rigorous analysis of the debate over GM versus non-GM crops is now needed. A fundamental flaw in most arguments (for example, the debate on substantial equivalence ${ }^{1,2}$ ) is the erroneous treatment of all genetically modified (GM) plants as one homogeneous group. This distorts arguments and weakens reasoning. It is time to introduce a classification of the distinctive types of GM crops. I propose the use of three classes:

(1) 'Wide transfer', referring to the movement of genes from organisms of other kingdoms into plants;

(2) 'Close transfer', referring to movements of genes between species of plants; and (3) 'Tweaking', referring to the manipulation of levels or patterns of expression of genes already present in a plant's genome.

Genetic modification, in its strictest meaning, has been performed for 10,000 years, including notably gross manipulations such as the development of hexaploid wheat and triticale. Consequently, I think it would also be sensible (and politically appropriate!) to refer to GM crops generated using modern biotechnology as 'new GM crops', as distinct from the 'old GM' of traditional breeding technologies.

Use of such terminology will throw into relief some of the more extreme claims made by both sides of the argument. For example, the use of 'substantial equivalence' (as employed for conventional crops) is most likely to be sufficient for crops developed using 'close transfer' and 'tweaking', as the results of these manipulations are unlikely to be different from processes used by traditional breeders. However, the introduction into the food chain of significant amounts of novel proteins by 'wide transfer' may well require more thorough testing, as for the introduction of a drug. If such tests were introduced only for plants generated by wide transfer, then the obvious objections to this suggestion raised by Anthony Trewavas and C. J. Leaver ${ }^{2}$ would not apply.

Use of a refined categorization of the new GM crops would focus arguments and facilitate more balanced conclusions in a currently unnecessarily polarized debate. Mark Tester

Department of Plant Sciences, University of Cambridge, Downing Street, Cambridge CB2 3EA, UK

Sir-Millstone et al. in their ill-informed Commentary "Beyond 'substantial equivalence" "1 advocate the use of extensive animal toxicology tests on whole
GM foods. But this type of testing has never been used to evaluate the safety of traditional, non-GM foods even though they often contain hundreds of unique proteins and other constituents. Such testing of whole foods would be tremendously unfocused, wasteful of laboratory animals, and unlikely to detect harmful substances, even if they were present.

The novel proteins in glyphosateresistant soya beans are present at very low levels, for example, and their effects, if any, would not be detected by feeding whole soya beans to lab animals. A focused approach aimed at these novel proteins identified through substantial equivalence would be much more reasonable. This is the approach that has been used and it clearly demonstrates the safety of these novel components. The rest of the soya bean is identical (or substantially equivalent) to traditional soya beans and, in our view, is safe for consumers.

Millstone et al. also suggest that glyphosate-resistant soya beans exposed to glyphosate may have different composition from traditional soya beans. In our view, such concerns are not particularly valid. The composition of specific components in specific crops, GM or non-GM, varies within a range as a result of variety, environmental/climatic conditions and agricultural practices. Soya beans exposed to glyphosate are not altered in composition beyond the normal range that exists naturally. And, even if they were, animal toxicology testing would be unlikely to reveal such differences.

Steve L. Taylor ${ }^{\star}$, Susan L. Hefle $\dagger$

${ }^{*}$ Department of Food Science and Technology,

143 Food Industry Complex, Lincoln,

New England 68583-0919, USA

$\dagger$ Food Allergy Research \& Resource Program,

Department of Food Science and Technology,

351 Food Industry Complex, Lincoln,

New England 68583-0919, USA

Sir - One reason for the unsatisfactory state of GM food regulation ${ }^{1}$ is the assumption, stated in the $\mathrm{FAO} / \mathrm{WHO}$ biotechnology and food safety report ${ }^{3}$ and adopted by UK regulators, that genetic engineering does not differ from conventional selective breeding. Hence, Trewavas and Leaver ${ }^{2}$ conclude that GM food should not be subject to more rigorous testing than novel non-GM food.

I believe this assumption is erroneous. Genetic engineering enables exotic genes from viruses and bacteria and other nonfood species to be introduced into food crops. These genes are combined in novel constructs, often with viral promoters to make genes overexpress continuously. The constructs are inserted into genomes by transformation techniques that cannot control where the genes go, resulting in a range of unpredictable positional effects and rearrangements. I would prefer to have a moratorium on environmental releases of GM material until safety issues have been more adequately and openly addressed. Mae-Wan Ho

Institute of Science in Society and Department of Biological Sciences, Open University, Walton Hall, Milton Keynes MK7 6AA, UK

Millstone et al. reply — Our Commentary ${ }^{1}$ on the use of the concept of substantial equivalence in evaluating the safety of GM foods has triggered a lively debate, but several correspondents have criticized us for things that we did not say, and in our view none of them has addressed our central argument that using substantial equivalence discourages vital scientific investigation.

Trewavas and Leaver ${ }^{2}$ and M. J. Gasson ${ }^{4}$ have suggested that we argued for full toxicity testing of all novel crop seeds in all potential circumstances of use. We did not make that assertion, but rather looked askance at an approval system that, if measured against the yardsticks of scientific rigour and public confidence, we believe is not adequate or effective. We also sought to unravel some of the reasons why confidence is lacking, and suggested ways in which the approvals system might be strengthened.

We do not agree with the view that single-gene changes necessarily result in well-characterized plant responses. For example, experimental genetic manipulation of oilseed crops, including rape, has led to the unexpected discovery of enzymes and regulatory mechanisms affecting lipid metabolism. Gasson's confidence that unexpected alterations in crop chemistry as a result of genetic modification are unlikely is contradicted by a report ${ }^{5}$ at a recent meeting that glyphosate tolerance in Roundup Ready soya beans appeared to be occurring at the expense of diminished heat tolerance as a result of changes to the lignin content. That research was triggered by the unexpectedly poor performance of Roundup Ready soya bean in hot climates, and it was only biological testing under various conditions that revealed the effect.

We totally reject the accusations made by Derek Burke ${ }^{6}$. Our Commentary contained no conspiracy allegation, nor did we criticize any individual — merely 'wishful thinking. There seems to be an unwillingness on the part of some enthusiasts for GM foods to engage with scientific challenges and policy questions such as those we posed. We are not demanding exhaustive toxicity tests. Rather, we hope to encourage a re-examination of what constitutes an adequate risk assessment for GM and other novel foods. This might help to improve public acceptance of the technology.

Erik Millstone $^{\star}$, Eric Brunner $\dagger$, Sue Mayer $\neq$ ${ }^{\star}$ SPRU — Science and Technology Policy Research, 
Mantell Building, University of Sussex, Brighton BN1 9RF, UK

$\dagger$ Department of Epidemiology and Public Health, University College London, London WC1E 6BT, UK $\ddagger$ GeneWatch UK, The Courtyard, Whitecross Road, Tideswell, Buxton, Derbyshire SK17 8NY, UK

1. Millstone, E., Brunner, E. \& Mayer, S. Nature 401, 525-526 (1999).

2. Trewavas, A. \& Leaver, C. J. Nature 401, 640 (1999).

3. Food \& Agriculture Organization/World Health Organization Biotechnology and Food Safety: Report of a Joint FAO/WHO Consultation (FAO, Rome, 1997).

4. Gasson, M. J. Nature 402, 229 (1999).

5. Getz, J. M., Venecil, W. K. \& Hill, N. S. The 1999 Brighton Conference 8C-6, 835-840 (British Crop Protection Council, Farnham, 1999)

6. Burke, D. Nature 401, 640-641 (1999).

\section{Why Diamond should go to Daresbury}

Sir - You report that the Wellcome Trust favours siting the new Anglo-French synchrotron source (Diamond) at the Rutherford Appleton Laboratory in southern England instead of at Daresbury Laboratory near Manchester (Nature 402, $451 ; 1999)$. I am concerned about Wellcome's statement that it is important to site Diamond close to the existing neutron spallation source (ISIS).

In fact, no protein-crystallography research is done on ISIS. Neutron proteincrystallography research is and will be conducted at the Institut Laue Langevin neutron source in Grenoble, France. I hold a Wellcome Trust research grant to work on both synchrotron X-ray proteincrystallography data collection and neutron protein-crystallography data collection. It has not been necessary to have $\mathrm{X}$-ray and neutron sources at the same location - it is simply not a requirement.

I am surprised that I have not been asked my opinion by anyone on the question of the siting of Diamond. Not only am I the chairman of the Institut Laue Langevin neutron beam-time biology review committee, but I have also chaired synchrotron $\mathrm{X}$-ray advisory committees for the European synchrotron radiation facility in France, Cornell in the United States and the Daresbury Synchrotron Radiation Source protein-crystallography beam panel.

I strongly support Daresbury as the site of Diamond. This vital project requires the vast body of experience among the staff at Daresbury Laboratory. The Rutherford Appleton Laboratory has its own expertise and is planning its own ISIS neutron source upgrades. But this is irrelevant to placing Diamond in the best UK location for its optimal, proper and successful development, which should be at Daresbury.

Finally, I warmly welcome the Wellcome Trust's involvement to the fullest extent possible in Diamond at Daresbury. The protein-crystallography programme on Diamond must be as vibrant as possible, given the importance of structural biology in the expanding fields of structure-based drug design and health care. The trust and the UK government research agencies are key players in this enterprise that should ensure the continuing international competitiveness of UK research and its pharmaceutical industry.

\section{John R. Helliwell}

Department of Chemistry, University of Manchester, Manchester M13 9PL, UK

\section{Seeking a guide to the quality of web writing}

Sir - The Opinion article "Dangers of over-dependence on peer-reviewed publication" presents an interesting perspective on an important debate (Nature 401, 727; 1999). It refers to a study on the problem of 'defining a publication' carried out by an international ad-hoc group under our joint chairmanship at the request of the science, technical and medical publishers, and presented to their recent meeting in Frankfurt. Far from blurring the concept of a publication, our proposals attempt to impose some order on the continuum of publication that has become possible in the electronic environment.

We acknowledge the variety of forms of scientific writing found on the Internet, and offer criteria for distinguishing among them, thereby giving readers a clearer basis than now exists for evaluating the status and credibility of whatever they are reading. We invite your readers to examine our discussion document (at the website http://associnst.ox.ac.uk/ icsuinfo/ aaas-stm.htm) and to contribute to the refinement or rebuttal of these ideas. Roger Elliott* ${ }^{\star}$, Mark S. Frankel $\dagger$ ${ }^{*}$ Chairman, ICSU Press, Department of Theoretical Physics, University of Oxford, 1 Keble Road, Oxford OX1 3NP, UK $\dagger$ American Association for the Advancement of Science, 1200 New York Avenue NW, Washington DC 20005, USA

\section{How ethical principles can aid research}

Sir - Søren Holm and John Harris argue that the precautionary principle stifles discovery (Nature 400, 398; 1999). I believe such a judgement to rely on a misunderstanding of the link between science and progress.

Discovery is by definition never selfevident: when a problem arises, the most apparently ready-made ways to solve it are likely to be the least productive in genuine novelty. This is precisely where moral issues come in, in science as in life in general. Real progress originates from the refusal to take a path that would threaten one's own moral choices and values. It is in such a situation, which to me is the essence of science as a daughter of ethics, that other ways do show up, not previously thought of, which lead to discovery. It is precisely the moral problem coming to the researcher's consciousness that alerts him to the fact that he is able to find another way. Not listening to the voice of consciousness in such a situation thus leads to missed discoveries. Therefore it is precisely in research that ethical principles are most useful.

So the precautionary principle should be viewed rather as a guide to avoid wrong directions, opening the way to better ones. Joël Sternheimer

Reseau Associatif de Chercheurs Independants, 1 rue Descartes, 75005 Paris, France

\section{Lobbying groups must be trustworthy}

Sir- I agree with H. Mohr that Greenpeace has no credibility when it comes to evaluating science (Nature 401, $524 ; 1999)$. Many of its activities and campaigns are based on propaganda rather than facts.

Academic research requires freedom from commercial competition and dependence. Mohr says he has enjoyed such freedom all his life, but this begs the question of whether this freedom is likely to be reduced if commercial interests arise. In cases where scientific results are open to different interpretations, scientists should not have a monopoly on opinion and answers, particularly on issues of public importance. Organizations representing the general public must have a say.

But these organizations must be trustworthy, rather than manipulating facts to suit their own agendas. People usually trust relief organizations, such as the Red Cross or Médecins sans Frontières, but these organizations generally avoid controversial issues. There are, however, numerous local organizations that are concerned with science in respect of both the environment and the production of food and other consumer goods. One example is Bellona in Oslo, recognized for its work with nuclear waste in the former Soviet Union. We need more of these types of organization at the international level, assuming they use acceptable methods.

Ketil Haarstad

Jordforsk, Norwegian Centre for Soil and Environmental Research, N-1432 As, Norway 